\title{
EVALUATION OF NOISE EXPOSURE BEFORE AND AFTER NOISE BARRIERS, A SIMULATION STUDY IN ISTANBUL
}

\author{
Nuri İLGÜREL ${ }^{\mathrm{a}}$, Neşe YÜĞRÜK AKDAĞ ${ }^{\mathrm{b}}$, Ali AKDAĞ ${ }^{\mathrm{c}}$ \\ ${ }^{a, b}$ Department of Architecture, Yildız Technical University, D-107, Beşiktaş, İstanbul, 34349 Turkey \\ 'Hidrotek Architecture and Engineering Ltd., İstanbul, Turkey
}

Submitted 19 Nov 2015; accepted 27 Apr 2016

\begin{abstract}
Turkish city in terms of the gradually worsening noise problems associated with the rapid increase in population. This study aims to investigate the noise exposure in the settlements around the link roads connecting the Bosporus Bridge to the European side of the city by the aid of simulations and noise mapping, in the frame of action planning studies performed in İstanbul. Noise maps were generated for $\mathrm{L}_{\text {den }}$ and $\mathrm{L}_{\mathrm{n}}$ noise indicators with the help of a noise mapping software. Since a considerable part of the settlements is exposed to high noise levels, a noise barrier alongside the link road was proposed as a control measure by the aid of the acoustic simulation. Simulations with the noise barriers suggest that for the $\mathrm{L}_{\mathrm{den}}$ time interval the noise affected area over $55 \mathrm{dBA}$ would reduce by $10 \%$, the number of dwellings by $26 \%$ and the number of inhabitants by $25 \%$, whereas for the $\mathrm{L}_{\mathrm{n}}$ time interval the noise affected area over $45 \mathrm{dBA}$ would reduce by $5 \%$, the number of dwellings by $20 \%$ and the number of inhabitants by $20 \%$.
\end{abstract}

Keywords: Bosporus Bridge, noise pollution, noise mapping, noise mitigation, noise barriers, noise indicators.

\section{Introduction}

Noise is an important environmental pollution factor that should be dealt seriously in accordance with the noise control strategies in order to mitigate it to the acceptable levels in the noise sensitive urban areas. Noise mitigation studies should be initially considered at the urban planning stage. Noise sources with different levels and characteristics and their location regarding the noise sensitive areas in the city are important decision factors at this stage.

In order of importance, measures for noise control should be taken first of all at the source, then between the source and the receiver, and finally at the receiver. While noise control measures are most effective and economic at the source, when this is not possible or sufficient, it may become important to implement other measures between the source and the receiver. In mitigation of urban noise, control of the noise generated by traffic flow on roads becomes crucial, since roads cover the city as a pervasive web and tend to affect noise sensitive urban areas. Thus, measures taken on the path of noise propagation, such as the use of noise barriers and improvement of building envelopes against noise are needed in addition to the arrangement of the roads and the traffic flow in a scientific manner. Today, the method of benefiting from noise maps for supply of statistical data about areas which are exposed to road noise is frequently applied in determination of necessary noise measures and development of effective solutions against noise. Noise maps, which offer the possibility to make predictions regarding the future, are considered a highly useful tool in planning urban development zones and determining the correct routes and locations for roads and other urban noise sources (Ibbeken, Krüger 2013).

Strategic noise maps are now required in the European Union for all population centres of more than 250,000 inhabitants, as well as for major roads, railways, and airports, and are becoming required for urban areas with over 100,000 people (END 2002). Debates surrounding environmental noise pollution with a particular focus on the European Union are gaining importance. Environmental noise pollution is an emerging public policy and environmental concern and is considered to be one of the most important environmental stressors affecting public health throughout the world. (Licitra 2013; Murphy, King 2014) In respect of noise mapping and action plans, there

Corresponding author: Nuri İlgürel

E-mail: milgurel@yildiz.edu.tr 
are many studies which may be taken as a model for the implementation of the Environmental Noise Directive in European countries and the utilization of noise maps (Blanes Guardia, Nugent 2013; Braunstein 2013; Ramírez, Domínguez 2013; Tracz, Wozniak 2013; Seong et al. 2011; King, Rice 2009).

In European countries, where related works still continue, 2nd phase of the studies were completed in 2012. As a European Union candidate country, Turkey made legal arrangements on the issue as well, and the national legislation for environmental noise management were revised. The Regulation on Environmental Noise Assessment and Management (RENAM 2010) which was prepared in harmony with the relevant European Directive (Directive 2002/49/EC), was published in the Official Journal of Turkey and put into force in July of 2005 and revised in 2010. The European Directive and the corresponding Turkish Regulation require noise mapping studies to be conducted for the evaluation of noise environment in urban areas. As the initial stage, RENAM stipulated the generation of noise maps until 31th of December, 2016 and development of related action plans until 31th of December, 2017 for settlements of more than 250,000 inhabitants, for major roads with annual traffic volume exceeding 6,000,000 motor-vehicles, for major railroads with annual traffic volume exceeding 60,000 trains and for major airports having more than 50,000 flights a year.

The European Commission has assigned a twinning project concerning the implementation of the Directive 2002/49/EC in Turkey to the Turkish Ministry of Environment and Forestry and the German Federal Ministry of Environment, Nature Conservation and Nuclear safety. Accordingly, noise maps and action plans have been developed for five pilot areas located in five major Turkish cities (Adana, Ankara, Bursa, İstanbul and İzmir) (Irmer et al. 2007). In another EU-supported project (Technical Assistance Project for Implementation Capacity for the Environmental Noise Directive), which addresses various noise sources in fourteen Turkish municipalities, noise mapping studies have been realized (Ministry of Environment and Urban Planning of Turkey 2015). The main purpose of the project is to strengthen the capacity of the stakeholders (Ministry of Environment and Urbanization, other ministries and relevant offices of municipalities) taking part in the field of noise management. As a leading research institution of Turkey, TUBITAK (Scientific and Technological Research Council of Turkey) has completed the generation of city noise maps for several cities. The institution also prepared noise maps for 13 Turkish airports and carries on related studies for 26 additional airports (TÜBİTAK MAM 2015; Özkurt et al. 2014; Sar1 et al. 2014).

According to the European Union Directive 2002/49/EC, acceptable noise levels for settlements are $55 \mathrm{dBA}$ for the whole day average including day, evening and night time intervals $\left(\mathrm{L}_{\mathrm{den}}\right)$, and $45 \mathrm{dBA}$ for the night time interval $\left(\mathrm{L}_{\text {night }}\right)$. It usually requires special measures to meet these acceptable levels in areas located around busy major roads. The purpose of this study is to exemplify the noise reduction potential of noise barriers, which may play an important role within the scope of environmental noise action plans, through a practical work carried out on access roads of the Bosporus Bridge. As a vital link between the European and Asian sides of Istanbul, the Bosporus Bridge has experienced an enormous increase of traffic density since its construction in 1973 (Fig. 1). In the practical study conducted for the area around the viaduct which serves as the European side connection of the bridge, noise maps were generated for the current situation by use of a simulation software and accuracy of the maps were validated through comparisons with the results of actual noise measurements. Afterwards, noise level reductions that can be obtained with the implementation of noise barriers were modelled on the noise maps and the results were evaluated by making comparisons with the current situation.

\section{Methodology}

The study was conducted in the following steps:

- Collection of data about the study area the road traffic.

- Generation of grid noise maps and statistical noise maps for the $L_{\text {den }}$ (day-evening-night) and $L_{n}$ (night) (23.00-07.00) time intervals, for the current situation.

- Validation of the accuracy of noise maps through comparisons with the results of actual noise measurements.

- Generation of grid noise maps and statistical noise maps for the $\mathrm{L}_{\text {den }}$ and $\mathrm{L}_{\mathrm{n}}$ time intervals, this time with the addition of noise barriers to the model.

- Comparative evaluation of the data for the current situation and the model with noise barriers.

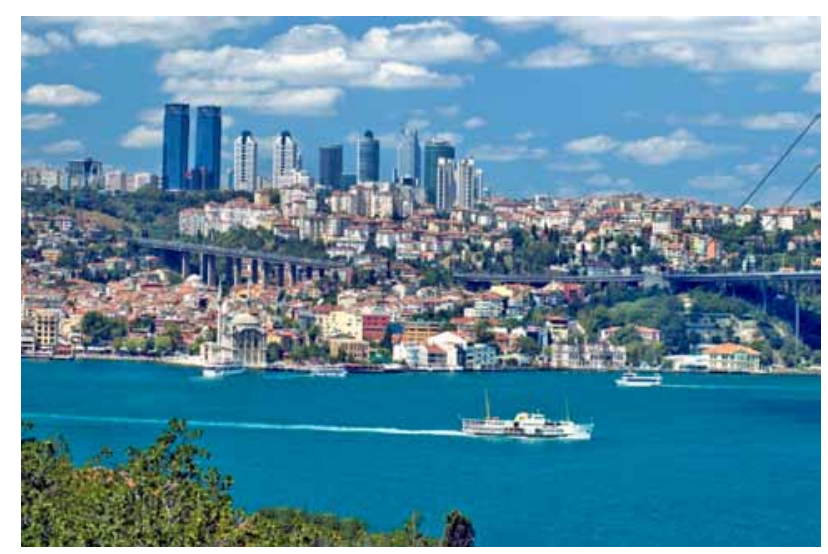

Fig. 1. General view of settlements around of the Bosporus Bridge in European side of İstanbul (wallpaperup 2014) 


\subsection{Collection of data about the study area and the road traffic}

Noise maps were generated in the SoundPLAN 7.3 simulation software (Braustain+Berndt GMBH 2006) for an area of approximately $3.5 \mathrm{~km}^{2}$ in order to reveal the noise problem experienced in the area in detail. For being able to generate accurate noise maps in the software, topography of the study area is required to be modeled as a beginning. Ready-to-use actual maps of the study area at the scale of $1 / 1000$ were provided by the Metropolitan Municipality of Istanbul in the digital environment. Digital maps which were prepared in the UTM coordinate system and contained necessary data regarding elevation ( $\mathrm{x}, \mathrm{y}, \mathrm{z}$ [height]) and the building information system (building use, number of floors, etc.) were loaded in the SoundPLAN 7.3 software. In order for the buildings in the area to be defined in the software, various formal and dimensional information including building height, number of floors and floor height, and other information including number of habitants were entered in the software for each building. Since the actual maps did not contain population data, total population of the area was equally distributed between the buildings, based on the data provided by the Turkish Statistical Institute (TUIK 2014).

For the purposes of simulation, prevailing and secondary winds observed in Istanbul were defined to be NNE and SSW respectively (Windfinder 2014); average temperature for the whole year was defined to be $15^{\circ} \mathrm{C}$ and average relative humidity was defined to be $70 \%$. The sound absorption value $(G)$ defined for the green fields in the study area was 0.6 as specified in the ISO 9613 standard (ISO 9613-2 1996).

Trucks, semi-trailers and other similar heavy vehicles are not allowed to use the Bosporus Bridge. Thus, heavy vehicle use of the bridge is limited to urban mass transportation means including busses and metro-busses. Latest data related to traffic volume on the bridge were released in 2012. However, 2012 was the year when the heavy vehicle traffic between two sides of the city was directed to the Bosporus Bridge during the evening and night time intervals, because the second bridge which is normally handling heavy vehicle traffic was temporarily put under maintenance works. For this reason, data for the year 2011 were preferred to be used in the study instead of the year 2012, and necessary updates were made on the data based on actual observations. Total number of vehicles passages on the bridge throughout the year 2011 was approximately 68,500,000 (Turkish Administration Privatization 2011). Table 1 shows the results of the observations which were carried out to provide up-to-date data regarding the number of vehicles using the bridge during certain hours of the day, evening and night time intervals in 2014. Since the traffic volume on the bridge does not differ significantly for monthly or daily variations, results of the observation in May 2014 were considered suitable for the purposes of the study. In addition, average traffic speed data were determined by performing experimental drives on the bridge. Traffic data of other primary and secondary roads in the area were also taken into account during the generation of noise maps.

In the preparation of noise maps, the NMPB Routes 96 (Guide de Bruit) standard was applied as the method of calculation, as recommended in the European Union Directive. Calculations were performed at a height of $4 \mathrm{~m}$ above ground and at grid dimensions of $10 \times 10 \mathrm{~m}$ as specified in the same Directive.

Table 1. Traffic data for the Bosporus Bridge

\begin{tabular}{ccccccc}
\hline $\begin{array}{c}\text { Time } \\
\text { inter- } \\
\text { val }\end{array}$ & Hours & $\begin{array}{c}\text { Light } \\
\text { vehicles } \\
\text { per } \\
\text { hour }\end{array}$ & $\begin{array}{c}\text { Heavy } \\
\text { vehicles } \\
\text { per } \\
\text { hour }\end{array}$ & $\begin{array}{c}\text { Light } \\
\text { vehicle } \\
\text { speed } \\
(\mathrm{km} / \mathrm{s})\end{array}$ & $\begin{array}{c}\text { Heavy } \\
\text { vehicle } \\
\text { speed } \\
(\mathrm{km} / \mathrm{s})\end{array}$ & $\begin{array}{c}\text { Propor- } \\
\text { tion of } \\
\text { heavy } \\
\text { vehicles } \\
(\%)\end{array}$ \\
\hline Day & $\begin{array}{c}17.00- \\
18.00\end{array}$ & 9475 & 225 & 50 & 50 & 2.4 \\
Eve- & $\begin{array}{c}19.00- \\
\text { ning }\end{array}$ & 11500 & 240 & 50 & 50 & 2.0 \\
Night & $\begin{array}{c}04.00- \\
05.00\end{array}$ & 3500 & 45 & 80 & 70 & 1.3 \\
\hline
\end{tabular}

\section{Determination of noise exposure in the current situation}

In Figure 2 and Figure 3, the grid noise map and statistical noise map for the $\mathrm{L}_{\text {den }}$ noise indicator are given for the current situation experienced in the area around the Bosporus Bridge link road. When the maps are reviewed, three main areas of dense settlements, which mainly consist of dwellings, are seen to be significantly affected by traffic noise. Level of noise affecting those areas are found to exceed $80 \mathrm{dBA}$ for $\mathrm{L}_{\text {den }}$ and $70 \mathrm{dBA}$ for $\mathrm{L}_{\mathrm{n}}$. The areas mostly affected by traffic noise are the settlements located on the ridges, as a result of the hilly terrain. In addition, dwellings around the Beşiktaş junction are seen to be under the effect of high noise levels. When it is remembered that the acceptable noise level is $45 \mathrm{dBA}$ for the night time and $55 \mathrm{dBA}$ for the day time, the whole population living in the area is understood to be exposed to unacceptable levels of noise. According to the statistical data given in Table 2 and based on the daily average figures, the number of inhabitants being subject to a noise level over $55 \mathrm{dBA}$ during the day time is 16,550 , while the number of inhabitants being subject to a noise level over $45 \mathrm{dBA}$ during the night time is 22,110 


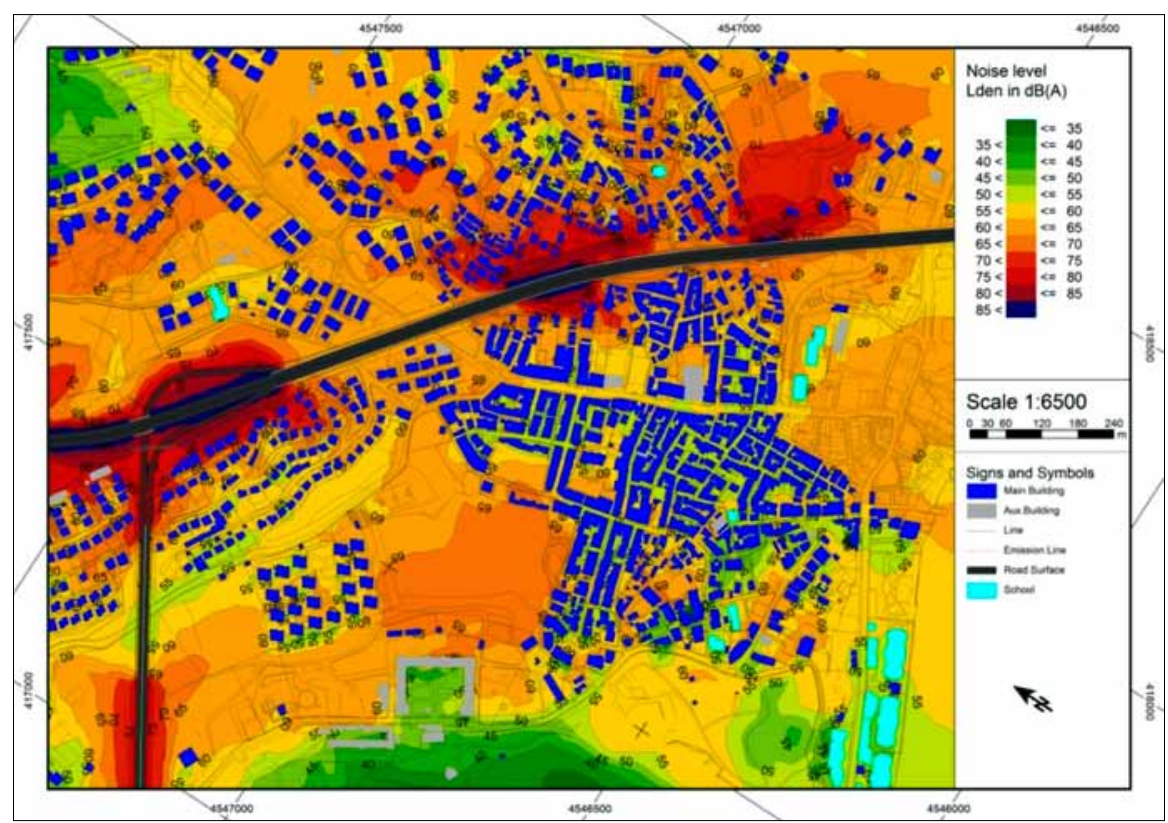

Fig. 2. Current situation noise map of the Bosporus Bridge link road for the day-eveningnight average $\left(\mathrm{L}_{\text {den }}\right)$

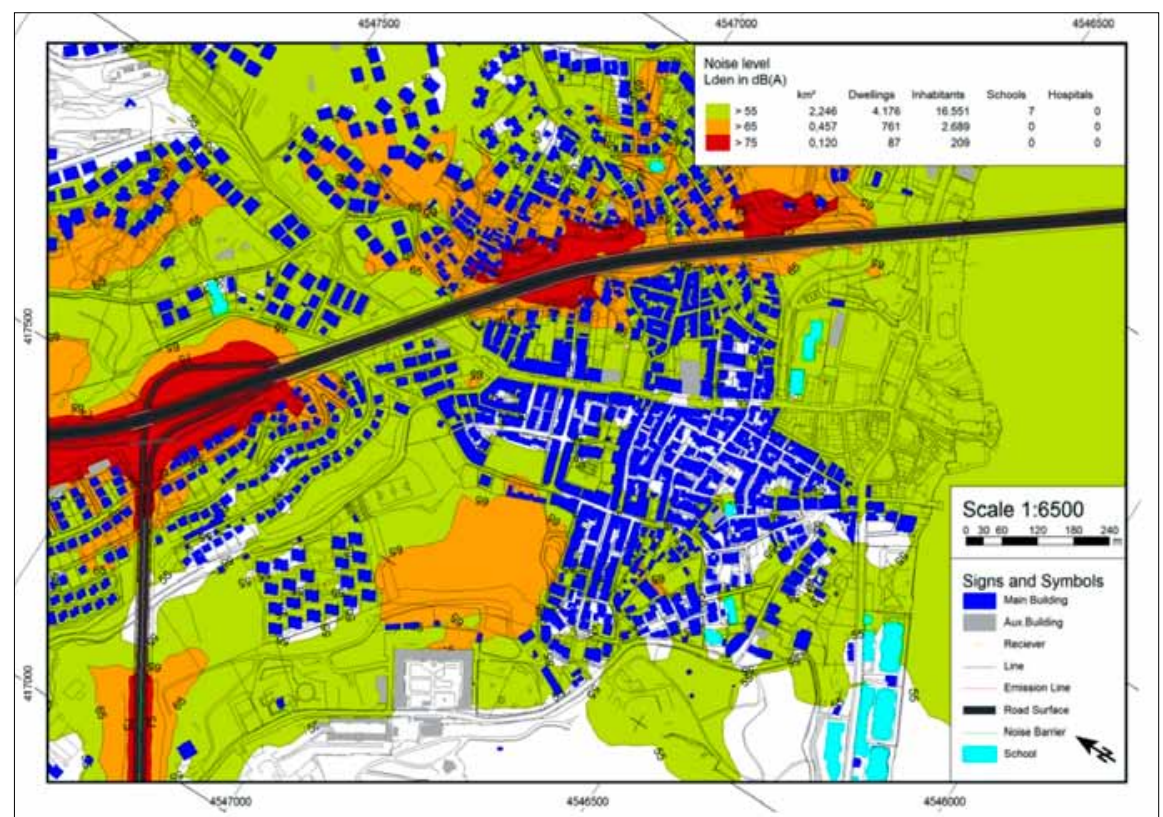

Fig. 3. Current situation statistical noise map for the day-evening-night average $\left(\mathrm{L}_{\mathrm{den}}\right)$

Table 2. Statistical values of exceeded noise levels in $\mathrm{L}_{\mathrm{den}}$ and $\mathrm{L}_{\mathrm{n}}$ for the current situation

\begin{tabular}{lccc|ccc}
\hline \multicolumn{2}{c}{ Time interval } & \multicolumn{2}{c}{$\mathrm{L}_{\text {den }}$ (day, evening, night average) } & & \multicolumn{2}{c}{$\mathrm{L}_{\mathrm{n}}$ (night) } \\
\hline \multicolumn{1}{c}{ Noise level } & $>55 \mathrm{dBA}$ & $>65 \mathrm{dBA}$ & $>75 \mathrm{dBA}$ & $>45 \mathrm{dBA}$ & $>55 \mathrm{dBA}$ & $>65 \mathrm{dBA}$ \\
\hline $\begin{array}{l}\text { Affected area } \\
\left(\mathrm{km}^{2}\right)\end{array}$ & 2.246 & 0.457 & 0.120 & 2.501 & 0.845 & 0.161 \\
$\begin{array}{l}\text { Affected number } \\
\text { of dwellings }\end{array}$ & 4200 & 761 & 87 & 5900 & 1410 & 210 \\
$\begin{array}{l}\text { Affected number } \\
\text { of inhabitants }\end{array}$ & 16550 & 2689 & 209 & 22110 & 5755 & 500 \\
\hline
\end{tabular}




\section{Noise measurements and validation of the model}

For realistic generation of noise maps, various data including topography of the study area, formal and dimensional properties of buildings, type of ground cover and properties of noise sources (parameters such as vehicle density and percentage of heavy vehicles and variation of traffic density in time for road noise) must be defined in the most accurate way possible in the simulation software. The most suitable method for validating the accuracy of a noise map is to carry out actual noise measurements and compare the actual results with the values calculated by the simulation. In our study, noise level measurements were performed at ten different points during both day and night time intervals for this purpose. Since the level of noise tends to decrease with higher densities of traffic due to the decrease in average vehicle speed, the measurements were carried out for day and night time intervals between the hours 11:00-13:00 and 24:00-02:00 respectively, when the measured noise levels rise to peak points

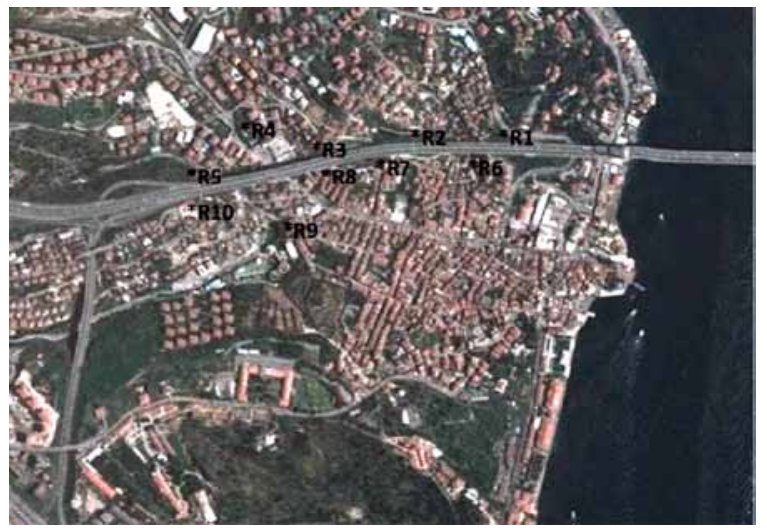

Fig. 4. Google Earth view of the European side link road of the Bosporus Bridge (2015) and noise measurement points for the whole day. Measurement points of measurements are seen in Figure 4. All measurements were performed in accordance with the ISO 1996-1 standard (ISO 1996-1 2003) in A-weighting by use of Brüel\&Kjær Type 2236 and Type 2258 sound level meters. Devices were placed to a height of $1.5 \mathrm{~m}$ above ground, at least $2 \mathrm{~m}$ away from any surface in order to eliminate the possibility of reflection, and windscreens were installed to the microphones. The results obtained through 15 minutes measurements and the data regarding number of vehicles are given in Table 3. On the other hand, spectral distribution of the noise measured for day time interval can be found in Figure 5 for the eight octave bands between $63 \mathrm{~Hz}$ and $8000 \mathrm{~Hz}$.

According to the observations of Maruyama et al., when the number of vehicles exceeds 170 , uncertainty indication $\Delta \mathrm{LAeq}_{\mathrm{T}}$ must be defined to be $\pm 1 \mathrm{~dB}$, independent from the time of measurement. In our study, number of vehicles passing was higher than 170 at all measurement points, hence the level of noise emitted from the

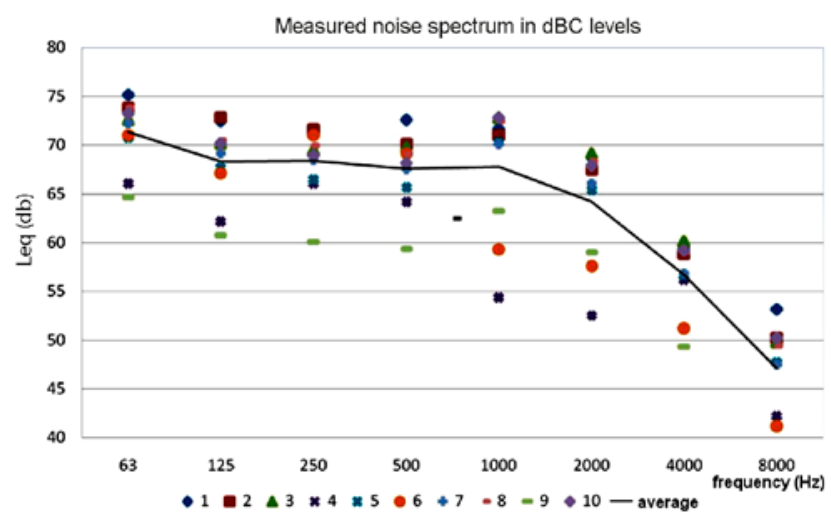

Fig. 5. Octave band noise levels measured on the European side link road of the Bosporus Bridge

Table 3. Noise measurement results and number of vehicles

\begin{tabular}{|c|c|c|c|c|c|c|c|c|c|c|c|}
\hline \multirow{2}{*}{$\begin{array}{l}\text { Measure- } \\
\text { ment time }\end{array}$} & \multirow{2}{*}{ Statistical evaluation } & \multicolumn{10}{|c|}{ Measurement points } \\
\hline & & 1 & 2 & 3 & 4 & 5 & 6 & 7 & 8 & 9 & 10 \\
\hline \multirow{6}{*}{ 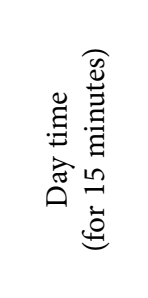 } & $\mathrm{L}_{\text {Aeq }}$ & 75.5 & 74.5 & 68.7 & 63.7 & 70.2 & 67.5 & 73.1 & 70.5 & 60.8 & 72.7 \\
\hline & $\mathrm{dBC}$ & 80.4 & 79.7 & 80.0 & 71.2 & 75.6 & 75.1 & 77.6 & 78.3 & 68.5 & 78.1 \\
\hline & $\mathrm{L}_{\mathrm{C}}-\mathrm{L}_{\mathrm{A}}$ & 4.9 & 5.2 & 7.9 & 7.5 & 5.4 & 7.6 & 4.5 & 7.8 & 7.7 & 5.4 \\
\hline & Number of vehicles & 2521 & 2451 & 2425 & 2356 & 2468 & 2471 & 2418 & 2436 & 2423 & 2476 \\
\hline & Heavy vehicles & 45 & 44 & 64 & 69 & 50 & 61 & 48 & 54 & 58 & 49 \\
\hline & Heavy vehicle (\%) & 1.75 & 1.76 & 2.57 & 2.85 & 1.99 & 2.41 & 1.95 & 2.17 & 2.34 & 1.94 \\
\hline \multirow{6}{*}{ 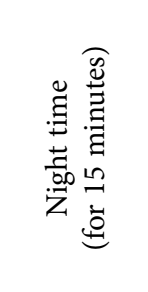 } & $\mathrm{L}_{\mathrm{Aeq}}$ & 71.3 & 69.6 & 65.7 & 58.7 & 63.2 & 64.5 & 69.2 & 61.5 & 57.8 & 64.5 \\
\hline & $\mathrm{dBC}$ & 73.4 & 72.2 & 70.1 & 62.6 & 66.4 & 69.0 & 71.4 & 66.3 & 63.6 & 67.4 \\
\hline & $\mathrm{L}_{\mathrm{C}}-\mathrm{L}_{\mathrm{A}}$ & 2.1 & 2.6 & 4.4 & 3.9 & 3.2 & 4.5 & 2.2 & 4.8 & 5.8 & 2.9 \\
\hline & Number of vehicles & 915 & 904 & 887 & 856 & 882 & 876 & 918 & 845 & 847 & 897 \\
\hline & Heavy vehicles & 6 & 8 & 12 & 15 & 14 & 16 & 7 & 9 & 21 & 8 \\
\hline & Heavy vehicle (\%) & 0.65 & 0.88 & 1.33 & 1.72 & 1.56 & 1.79 & 0.76 & 1.05 & 2.42 & 0.88 \\
\hline
\end{tabular}


road can be accepted to be between 60.8 and $75.5 \mathrm{dBA}$ with an approximation of $\pm 1 \mathrm{~dB}$ (Maruyama et al. 2012; Garg, Maji 2014).

Viaducts and bridges are known to be subject to vibration during the passage of vehicles because of their separate decks sitting on piers, which may cause significant increases on the level of low frequency noise. Vehicle number counting studies reveal a heavy vehicle proportion of $1.3-2.4 \%$ on the Bosporus Bridge. However, this figure does not consist of heavy trucks of semi-trailers, which may cause high amplitude vibration of the bridge deck and create dominant low frequency noise as a result, but of busses, metro-busses and smaller trucks. As can be seen in Table 3, $\mathrm{L}_{\mathrm{c}}-\mathrm{L}_{\mathrm{A}}$ values vary between $4.5-7.9 \mathrm{~dB}$ for $\mathrm{L}_{\text {den }}$ and between $2.1-5.8 \mathrm{~dB}$ for $\mathrm{L}_{\mathrm{n}}$ time intervals. Since the $\mathrm{L}_{\mathrm{c}}-\mathrm{L}_{\mathrm{A}}$ value is lower than $8 \mathrm{~dB}$ at all measurement points, it can be foreseen that any significant disturbance will not be experienced in the area in terms of low frequencies, when noise barriers are installed on the bridge (Ascari et al. 2015).

For the purpose of validation of the noise maps generated, single point receiver calculations were performed by the software for the $L_{d}$ and $L_{n}$ time intervals for the actual measurement points, at an elevation of $1.5 \mathrm{~m}$ above ground and with different distances to the highway. Results of the calculations made by the SoundPLAN 7.3 software are given in Table 4, together with the results of actual measurements. For day time interval the measured noise levels vary between $60.8-75.5 \mathrm{dBA}$ with a standard deviation of 4.70 , while for night time interval between 57.8-71.3 dBA with a standard deviation of 4.53. The differences between the calculated and measured levels vary for day time interval between (-0.3)-(1.4) dB according to the measurement point with a standard deviation of 1.08 , while for night time interval between $(-0.3)-(1.5) \mathrm{dB}$ with a standard deviation of 0.93 . The calculated levels are in good agreement with the measured levels for both time intervals, since the differences between measured and calculated levels are sufficiently small.
According to the Good Practice Guide for Strategic Noise Mapping and the Production of Associated Data on Noise Exposure (WG-AEN 2006), the difference between actual measurement results and the figures presented by the model must not exceed $1 \mathrm{~dB}$ in a distance of $300 \mathrm{~m}$ from the source, $3 \mathrm{~dB}$ in a distance of $600 \mathrm{~m}$ from the source and $10 \mathrm{~dB}$ in a distance of 2,000-3,000 $\mathrm{m}$ from the source. As can be seen in Table 4, highest difference between measured and calculated noise levels is $1.5 \mathrm{dBA}$, which easily validates the reliability of the results presented by the simulation.

\section{Determination of noise exposure after the addition of noise barriers to the model}

In order to propose a solution for the negative effects of noise on the settlements located around the Bosporus Bridge link road, noise barriers were virtually designed for both sides of the road and additional noise maps were generated for the new scenario with noise barriers. The attributes of the designed noise barriers are as follows:

- According to the simulations the length of the noise barriers should be $900 \mathrm{~m}$. from the joining point of the bridge on the European side to the junction point of the roads in order to protect the settlement zones from noise.

- Noise level decrease for $2 \mathrm{~m}, 3 \mathrm{~m}$ and $4 \mathrm{~m}$ high barriers have been calculated, nevertheless $4 \mathrm{~m}$ high barrier was not significantly efficient as compared to others with very small gains in noise level decrease. Thus, $3 \mathrm{~m}$ high barrier was chosen for noise mapping process.

- In order to minimize the over-height visual effect of the barrier and increase the barrier effectiveness, the barriers were designed as; the lower $2 \mathrm{~m}$ vertical part made of opaque materials and the upper 1 $\mathrm{m}$ transparent part slopped $10^{\circ}$ to the road side.

- In order to minimize the reflections the lower part of the barrier facing the road side was designed sound absorbent (load bearing structure + sound

Table 4. Noise measurement data and calculation statistics

\begin{tabular}{|c|c|c|c|c|c|c|c|c|c|c|c|c|}
\hline \multirow{3}{*}{$\begin{array}{l}\text { Mea- } \\
\text { sure- } \\
\text { ment } \\
\text { time }\end{array}$} & \multirow{2}{*}{$\begin{array}{c}\begin{array}{c}\text { Statistical } \\
\text { evaluations }\end{array} \\
\text { Measurement points }\end{array}$} & \multicolumn{10}{|c|}{ Measured and calculated levels } & \multirow{3}{*}{$\begin{array}{l}\text { Stan- } \\
\text { dard } \\
\text { devia- } \\
\text { tion }\end{array}$} \\
\hline & & 1 & 2 & 3 & 4 & 5 & 6 & 7 & 8 & 9 & 10 & \\
\hline & $\begin{array}{l}\text { approx. distance to } \\
\text { the highway }(\mathrm{m})\end{array}$ & 11 & 14 & 18 & 60 & 12 & 22 & 2 & 2 & 70 & 8 & \\
\hline \multirow{3}{*}{$\begin{array}{l}\text { Day } \\
11: 00- \\
13: 00\end{array}$} & Measured LAeq & 75.5 & 74.5 & 68.7 & 63.7 & 70.2 & 67.5 & 73.1 & 70.5 & 60.8 & 72.7 & 4.70 \\
\hline & Calculated LAeq & 74.8 & 74.1 & 70.0 & 62.8 & 71.3 & 68.5 & 72.0 & 69.1 & 59.7 & 73.0 & 4.86 \\
\hline & Difference & 0.7 & 0.4 & -1.3 & 0.9 & -0.9 & -1.0 & 1.1 & 1.4 & 1.1 & -0.3 & 1.08 \\
\hline \multirow{3}{*}{$\begin{array}{l}\text { Night } \\
24: 00- \\
02: 00\end{array}$} & Measured LAeq & 71.3 & 69.6 & 65.7 & 58.7 & 63.2 & 64.2 & 69.2 & 61.5 & 57.8 & 64.5 & 4.53 \\
\hline & Calculated LAeq & 71.8 & 68.8 & 65.0 & 57.5 & 63.5 & 62.7 & 70.3 & 62.3 & 57.2 & 64.0 & 4.91 \\
\hline & Difference & -0.5 & 0.8 & 0.7 & 1.2 & -0.3 & 1.5 & -1.1 & -0.8 & 0.6 & 0.5 & 0.93 \\
\hline
\end{tabular}


absorbing materials + perforated metal plates) and the upper part slopped.

- The mass of the lower part of the barrier should be nearly $24 \mathrm{~kg} / \mathrm{m}^{2}$ for sufficient high sound transmission loss.
Figure 6 and Figure 7 show the grid noise map and statistical noise map generated for $\mathrm{L}_{\mathrm{den}}$ noise indicator after the implementation of the noise barrier in the software.

Table 5 shows the values of noise exposure for the day-evening-night and night time intervals in terms of

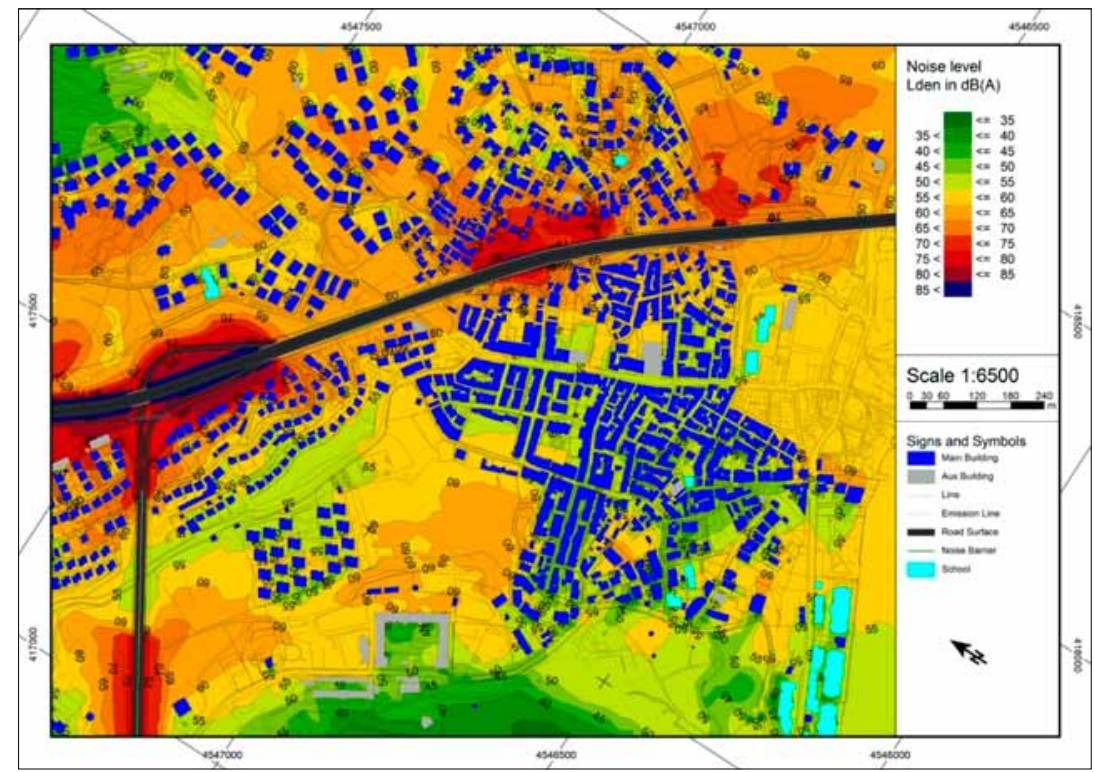

Fig. 6. Bosporus Bridge link road noise map for the day-evening-night average $\left(\mathrm{L}_{\mathrm{den}}\right)$ with noise barriers

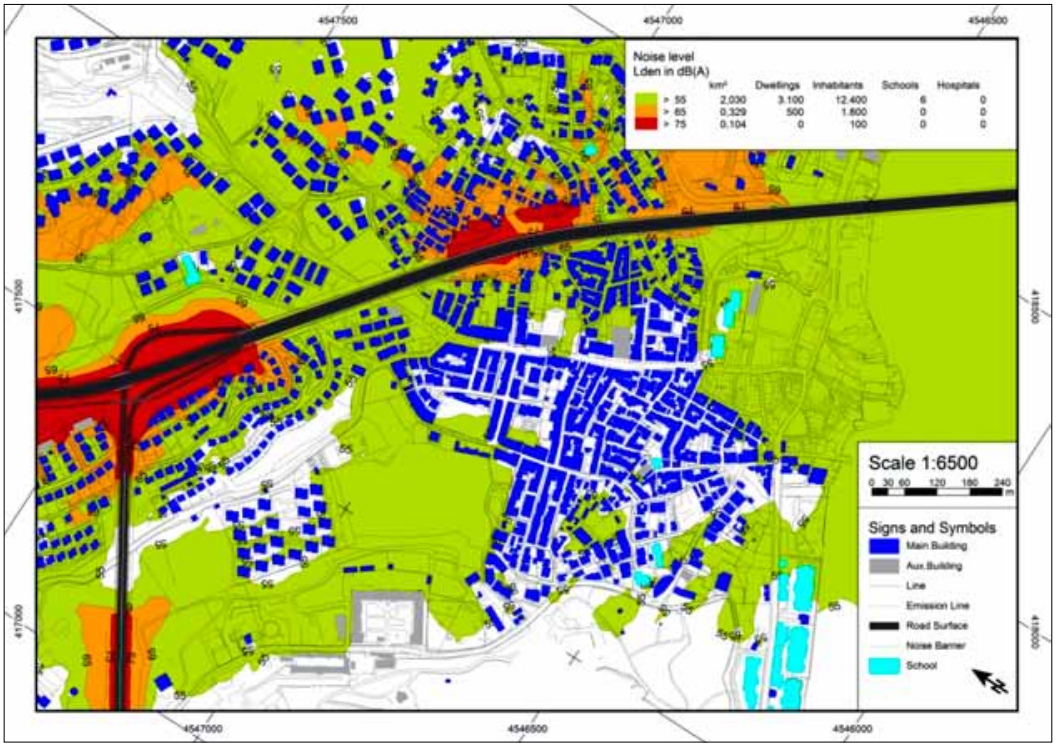

Fig. 7. Statistical noise map for the day-evening-night average $\left(\mathrm{L}_{\mathrm{den}}\right)$ with noise barriers

Table 5. Noise exposure values for $\mathrm{L}_{\mathrm{den}}$ and $\mathrm{L}_{\mathrm{n}}$ time intervals with noise barrier

\begin{tabular}{lcccccc}
\hline \multicolumn{1}{c}{ Time interval } & \multicolumn{2}{c}{$\mathrm{L}_{\mathrm{den}}$ (day, evening, night average) } & \multicolumn{3}{c}{$\mathrm{L}_{\mathrm{n}}$ (night) } \\
\hline Noise level & $>55 \mathrm{dBA}$ & $>65 \mathrm{dBA}$ & $>75 \mathrm{dBA}$ & $>45 \mathrm{dBA}$ & $>55 \mathrm{dBA}$ & $>65 \mathrm{dBA}$ \\
Affected area $\left(\mathrm{km}^{2}\right)$ & 2.030 & 0.329 & 0.104 & 2.377 & 0.587 & 0.133 \\
Affected number of dwellings & 3087 & 466 & 35 & 4708 & 905 & 112 \\
Affected number of inhabitants & 12450 & 1770 & 121 & 18116 & 3705 & 205 \\
\hline
\end{tabular}




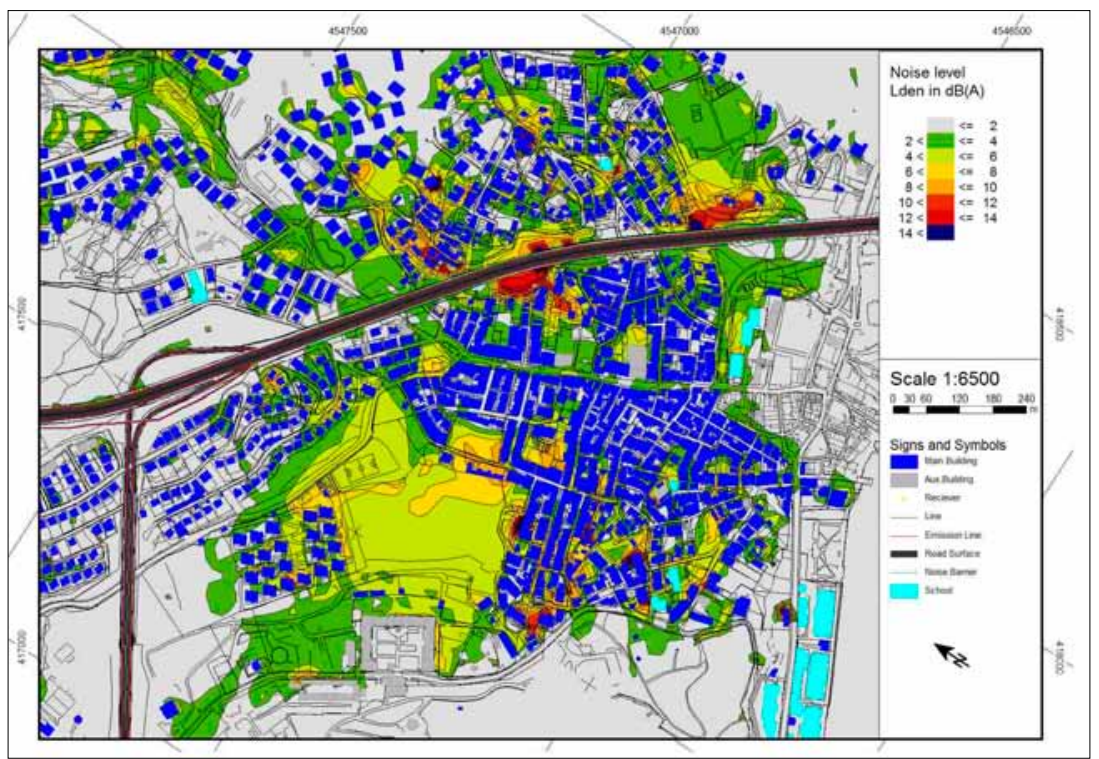

Fig. 8. Reduction in the level of exposure obtained with the addition of noise barriers to the model

affected area, number of dwellings and number of inhabitants, based on the data provided by the statistical noise maps generated with noise barriers.

\section{Conclusions}

1. Figure 8 shows the noise reduction obtained with the addition of noise barriers to the model, in comparison with the current situation without any barrier. Lower elevation of the section on the south-western side of the bridge is understood to enhance the effectiveness of barriers. In this section, the reduction provided by noise barriers falls below $2 \mathrm{~dB}$ after an approximate distance of $500 \mathrm{~m}$ from the bridge. On the other hand, on the northeastern side of the bridge, which has a higher elevation than the bridge, effective range of noise barriers is seen to be limited to around $250 \mathrm{~m}$. When the area is evaluated as a whole, many buildings are found to benefit from a reduction of noise between 2 and $4 \mathrm{dBA}$, certain regions are seen to obtain higher reductions as a result of their favourable topographic and settlement conditions, and the level of noise effecting a small plot close to the bridge is seen to be up to $14 \mathrm{dBA}$ lower than the current situation without barriers.

2. Figure 9 and 10 reveal exposure conditions of the area in terms of affected area, dwellings and inhabitants in the $\mathrm{L}_{\text {den }}$ and $\mathrm{L}_{\mathrm{n}}$ time intervals, with and without noise barriers. These two graphs indicate changes in the affected parameters in terms of the area, dwelling and population. Since the affected noise levels before and after barrier states can be assessed by using these different types of parameters, they have been shown on individual graphs for the $\mathrm{L}_{\text {den }}$ and $\mathrm{L}_{\mathrm{n}}$ noise indicators in order to easy the comparison between them.

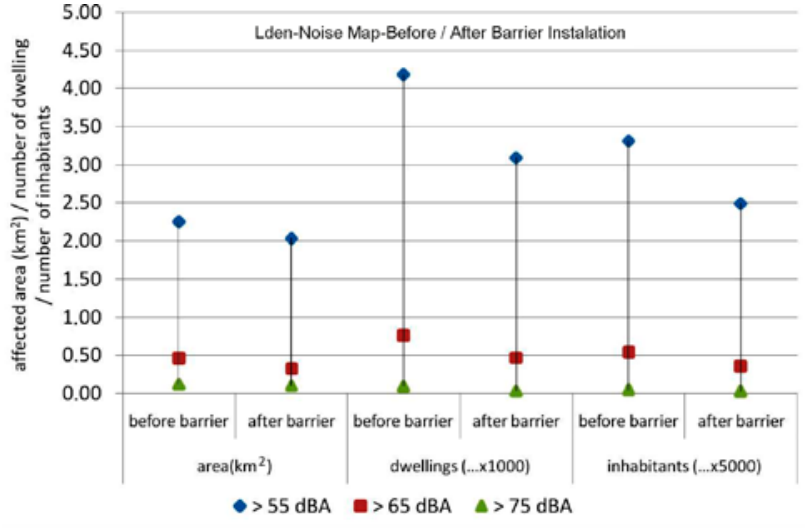

Fig. 9. Changes in figures of affected area-dwellings-habitants in the day-evening-night $\left(\mathrm{L}_{\text {den }}\right)$ time interval with the addition of noise barriers to the model. (e.g. number of dwellings exposed to noise before barrier over $65 \mathrm{dBA}$ is calculated approx. by $0.8^{\star} 1000=800$ )

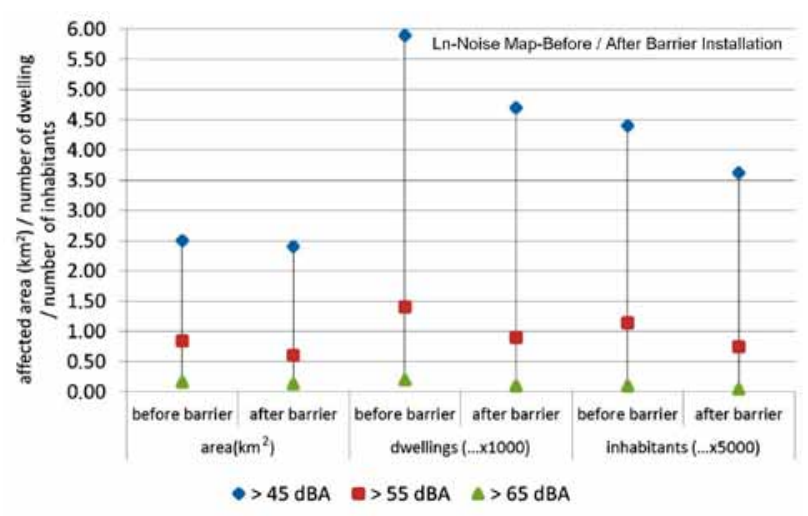

Fig. 10. Changes in numbers of affected area-dwellingshabitants in the night $\left(\mathrm{L}_{\mathrm{n}}\right)$ time interval with the addition of noise barriers to the model. (e.g. number of dwellings exposed to noise before barrier over $55 \mathrm{dBA}$ is calculated approx. by $\left.1.4^{\star} 1000=1400\right)$ 
When the graphs in Figure 9 and 10 are reviewed, it is seen that construction of the proposed noise barrier can provide a certain amount of improvement in terms of the amount of area, number of dwellings and inhabitants being exposed to excessive noise levels. When a threshold exposure value for Lden is considered as $55 \mathrm{dBA}$, number of inhabitants being exposed to excessive noise levels can be reduced by $25 \%$, from 16,550 to 12,450 , by the aid of the noise barrier. When the same comparison is made for a threshold exposure value of $65 \mathrm{dBA}$, number of inhabitants affected can be reduced by $35 \%$, from 2,689 to 1,770 . For the threshold value of $75 \mathrm{dBA}$, reduction reaches to $42 \%$, with the number of inhabitants affected decreasing from 209 to 121. At the night time interval, the number of dwellings being exposed to noise can be reduced by $19 \%$ for the $45 \mathrm{dBA}$ threshold, $35 \%$ for the $55 \mathrm{dBA}$ threshold and $59 \%$ for the $65 \mathrm{dBA}$ threshold.

3. Simulations with the noise barriers suggest that the number of people in the acceptable noise exposure area would increase as to cover 4100 people more than before barrier; considering the acceptable noise levels for $\mathrm{L}_{\text {den }}$ and $\mathrm{L}_{\mathrm{n}}$ indicators determined as $55 \mathrm{dBA}$ and $45 \mathrm{dBA}$ respectively.

4. According to the simulations made it is obvious that the barrier efficiency, which is determined by the degree of the noise level decrease, is significantly influenced by the topography and vegetation; for instance at the upper parts of the sloped hills the decrease in noise levels due to the barrier gets smaller in accordance with the diminishing acoustic shadow effect of the barrier.

5. It is well known that low frequency components of noise enhance with the addition of the noise barriers on the edges of the viaduct, especially vibrations caused by heavy vehicles are effective. In order to avoid this undesirable effect the noise barriers to be placed on the viaduct should be constructed by using structure components not too heavy but rigid (Monazzam, Nassiri 2009; Monazzam 2009). That is one of the reasons why the noise barrier was not designed homogenous in this study, instead from two different components; one is opaque and the other is transparent.

6. As seen in most cities of the world, inhabitants in Turkey spend most of their time under exposure to unacceptable levels of noise. For being able to create desirable acoustic environments, many further studies similar to the one exemplified in this paper must be conducted at higher levels of detail, and action plans must be carried into practice based on the results.

7. Many Turkish cities do not have maps in GIS format, while a significant proportion of existing maps can only provide inadequate or outdated data. Inadequacy of data in terms of noise sources is another important problem encountered in the course of noise mapping studies.
8. Accordingly, municipalities being in the first place, many institutions and organizations in Turkey continue their efforts towards filling the gap of available data. It is thought that noise mapping and action planning works can be performed much more rapidly when these important priorities are met.

\section{References}

Ascari, E.; Licitra G.; Teti, L.; Cerchiai, M. 2015. Low frequency noise impact from road traffic according to different noise prediction methods, Science of the Total Environment 505: 658-669. http://dx.doi.org/10.1016/j.scitotenv.2014.10.052

Blanes Guardia, N.; Nugent, C. 2013. Overview of the current state of the environmental noise directive implementation in Europe and exploitation of results, in Proceedings of InterNoise 2013, 15-18 September 2013, Innsbruck, Austria.

Braustain+Berndt GMBH. 2006. SoundPLAN Manual V 7.3. Backnang: Braustain+Berndt GMBH.

Braunstein, G. 2013. Suitable tools for the optimization of the modelling large noise maps and a discussion about the selection of appropriate input data, in Proceedings of Inter-Noise 2013, 15-18 September 2013, Innsbruck, Austria.

END. 2002. ENC Directive 2002/49/EC relating to the assessment and management of environmental noise, Official Journal of European Communities, L189. 14 p. [online], [cited 04 November 2015]. Available from Internet: http://www. noiseproject.gen.tr/uploads/files/Ek_VI_Noise\%20EU\%20 Directive.pdf

Garg, N.; Maji, S. 2014. A critical review of principal traffic noise models: strategies and implications, Environmental Impact Assessment Review 46: 68-81.

http://dx.doi.org/10.1016/j.eiar.2014.02.001

Ibbeken, S.; Krüger, M. 2013. Noise mapping of major roads for the state of Baden-Wuerttemberg according to the EU Environmental Noise Directive, in Proceedings of Inter-Noise 2013, 15-18 September 2013, Innsbruck, Austria.

Irmer, V.; Öncüer, B.; Saral, S.; Yükcel, H. 2007. Noise mapping in Turkey-implementation of the environmental noise directive, in Proceedings of Inter-Noise 2007, 28-31 August 2007, İstanbul, Turkey.

ISO 9613-2:1996. Acoustics - Attenuation of sound during propagation outdoors - part 2: general method of calculation. International Organization for Standartization, Geneva.

ISO 1996-1:2003. Acoustics - Description, measurement and assessment of environmental noise - part 1: basic quantities and assessment procedures. International Organization for Standartization, Geneva.

King, E. A.; Rice, H. J. 2009. The development of a practical framework for strategic noise mapping, Applied Acoustics 70(8): 1116-1127. http://dx.doi.org/10.1016/j.apacoust.2009.01.005

Licitra, G.; 2013. Noise mapping in the EU: models and procedures. USA: CRC Press. http://dx.doi.org/10.1201/b12885

Maruyama, M.; Kuna, K.; Sone, T. 2012. The minimum measurement time for estimating $\mathrm{L}_{\mathrm{AeqT}}$ of road traffic noise from the number of vehicles pass-bys, Applied Acoustics 74(3): 317-24. http://dx.doi.org/10.1016/j.apacoust.2012.08.005 
Ministry of Environment and Urban Planning of Turkey. 2015. Technical Assistance Project for Implementation Capacity for the Environmental Noise Directive. EuropeAid/131352/D/ SER/TR [online], [cited 04 November 2015]. Available from Internet: http://www.noiseproject.gen.tr/en/about-project/5

Monazzam, M. R.; Nassiri, P. 2009. Performance of profiled vertical reflective parallel noise barriers with quadratic residue diffusers, International Journal of Environmental Research 3(1): 69-84.

Monazzam, M. R. 2009. Optimization of profiled diffuser barrier using the new multi-impedance discontinuities model, International Journal of Environmental Research 3(3): 327-334.

Murphy, E.; King; E. A. 2014. Environmental noise pollution. Noise Mapping, Public Health and Policy. USA, Elsevier Inc. http://dx.doi.org/10.1016/B978-0-12-411595-8.00001-X

Özkurt, N.; Sarı, D.; Akdağ, A.; Kütükoğlu, M.; Gürarslan, A. 2014. Modelling of noise pollution and estimated human exposure around İstanbul Atatürk Airport in Turkey, Science of the Total Environment 482-483: 486-492.

http://dx.doi.org/10.1016/j.scitotenv.2013.08.017

Ramirez, A.; Dominguez, E. 2013. Modelling urban traffic noise with stochastic and deterministic traffic models, Applied Acoustics 74(4): 614-621. http://dx.doi.org/10.1016/j.apacoust.2012.08.001

RENAM. 2010. Regulation of Environmental Noise Assessment and Management, The Official Gazette No. 25862. Turkey (in Turkish).

Sarı, D.; Özkurt, N.; Hamamcı, S. F.; Ece, M.; Yalçındağ, N.; Akdağ, A.; Akdağ, N. Y. 2014. November. Assessment of noise pollution sourced from entertainment places in Antalya, Turkey, in Proceedings of Inter-Noise 2014, 16-19 November 2014, Melbourne, Australia.
Seong, J. C.; Park, T. H.; Ko, J. H.; Chang, S. I.; Kim, M.; Holt, J. B.; Mehdi, M. R. 2011. Modelling of road traffic noise and estimated human exposure in Fulton Country, Georgia, USA, Environmental International 37: 1336-1341. http://dx.doi.org/10.1016/j.envint.2011.05.019

Tracz, M.; Wozniak, K. 2013. Use of noise maps in designing of bypass vertical alignment in relation to housing location, in Proceedings of Inter-Noise 2013, 15-18 September 2013, Innsbruck, Austria.

TUIK. 2014. Document of regional accounts statistics [online]. Turkish Statistical Institute [cited 10 April 2014]. Available from Internet: http://www.turkstat.gov.tr/PreTabloarama.do

Turkish Administration Privatization. 2012. Presentation document of highways and bridges privatization [online], [cited 10 October 2015]. Available from Internet: http://www.oib.gov. tr/2011/dosyalar/otoyollar_tanitim_Ocak_2011.pdf

TÜBİTAK MAM. 2015. Projects [online], [cited 1 February 2015]. Available from Internet: http://ctue.mam.tubitak.gov. tr/en/ arastirma-alanlari/projects

wallpaperup [online]. 2014 [cited 10 August 2014]. Available from Internet: http://www.wallpaperup.com/349001/ Istanbul citysea_of_marmara_night_bosphorus_bridge_turkey. html

WG-AEN. 2006. Good practice guide for strategic noise mapping and the production of associated data on noise exposure [online], European Commission Working Group Assessment of Exposure to Noise [cited February 2015]. Available from Internet: http://ec.europa.eu/environment/noise/pdf/wg_aen. pdf

Windfinder [online]. 2014 [cited 10 February 2014]. Available from Internet: http://www.windfinder.com

Nuri İLGÜREL graduated in 2000 from the Department of Architecture at Balıkesir University. He attained his MSc degree in 2004 and PhD degree in 2010 in "Building Physics" at the Department of Architecture at the Ylldiz Technical University (YTU). He became Assoc. Professor in 2014 and he continues his research studies at the Building Physics Unit of the Department of Architecture at YTU. He has profession in Noise Control and Architectural Acoustics. He has many national and international publications in his field. He is a member of the Turkish Acoustical Society.

Neşe YÜĞRÜK AKDAĞ studied at Yildiz Technical University and obtained a degree in Architecture in 1984, an MSc degree in "Building Physics" in 1987, and received her PhD in "Architectural Acoustics" from Yildiz Technical University in 1995. She is full professor since 2011 in Building Physics Unit of the Faculty of Architecture in Yildiz Technical University. She has range of articles, papers, books and applications on room and building acoustics. She has also several researches on noise mapping. She prepared and organized some national projects and contributed to several national and international projects. She is a member of the Turkish Acoustical Society.

Ali AKDAĞ graduated in 1985 in Electronics and Communication Engineering at Istanbul Technical University. He received his MSc degree in 1989. He is owner of Hidrotek Mimarlik Muh. Tic. Ltd. He is providing training services for the preparation of noise maps and projecting noise prevention measures. He has involved several noise mapping projects like noise mapping of 31 airports in cooperation with TUBITAK Marmara Research Center, Environment and Cleaner Production Institute and strategic noise mapping of several cities in Turkey. 